\title{
Blood Transfusion Service in the Czech Republic - Organization, Regulation and Guidelines, Quality and Safety, Perspectives and Challenges
}

\author{
Renata Zimováa Petr Turek ${ }^{b}$ \\ a State Institute for Drug Control, \\ ${ }^{b}$ Blood Transfusion Department, General Teaching Hospital, Prague, Czech Republic
}

\section{Key Words}

Blood transfusion service $\cdot$ Czech Republic

\section{Summary}

The Czech Republic became EU member in 2004. Blood transfusion service is hospital based and dispersed. The Czech Republic is self-sufficient in blood components and plasma for fractionation. Donor population constituting mostly of voluntary non-remunerated blood donors is stable and relatively safe. A total of 19 HIV-positive donors have been detected during last 20 years, the incidence for HBV and $\mathrm{HCV}$ in blood donors in 2004 is below 0.15 and $0.25 \%$, respectively. European standards have been accepted and implemented during the last 15 years. Donor and blood collection, as well as processing and testing comply with EU directives. The manufacturers of blood components are under control of the state authority (State Institute for Drug Control). Recommendations based on expert opinion are available for clinical use of blood. Adverse effects of treatment are followed and investigated. Costs of blood components and plasma products are covered by general health insurance.

\section{Introduction}

The Czech Republic is a country in the middle of Europe with 10.3 million inhabitants and $80,000 \mathrm{~km}^{2}$. It became EU member in 2004. Blood transfusion service is hospital based and dispersed. Blood is collected mostly from voluntary non-remu-

\author{
Schlüsselwörter \\ Bluttransfusionsdienst . Tschechische Republik
}

\section{Zusammenfassung}

Im Jahre 2004 wurde die Tschechische Republik Mitglied in der EU. Der Transfusionsdienst ist in den Krankenhäusern untergebracht und weitgehend zersplittert. In Bezug auf Blutkomponenten und Plasma kann das Land den Eigenbedarf decken. Die Spenderpopulation setzt sich zumeist aus freiwilligen Blutspendern zusammen und ist stabil und relativ sicher. Die Inzidenz von Krankheiten, die durch Transfusion übertragen werden, ist niedrig. Insgesamt wurden 19 HIV-positive Spender in letzten 20 Jahren entdeckt, die Inzidenz für HBV in der Spenderpopulation lag im Jahr 2004 bei $0,15 \%$ o und für HCV bei $0,25 \%$. Die europäischen Standards wurden in den letzten 15 Jahren akzeptiert. Spenderauswahl, Blutabnahme, Bearbeitung und Testung entsprechen den EU-Direktiven. Die Blutkomponentenhersteller werden von staatlichen Autoritäten (Staatsinstitut fur Arzneimittelkontrolle) kontrolliert. Für die klinische Verwendung von Blut und Blutkomponenten gibt es Empfehlungen, die auf der Expertenmeinungen beruhen. Unerwünschte Reaktionen der Behandlung werden verfolgt und untersucht. Die Kosten von den Blutkomponenten und Plasmaprodukten werden von den Krankenkassen übernommen.

nerated blood donors, and the country is self-sufficient in blood components and plasma for fractionation. The donor population is stable and relatively safe. A total of $19 \mathrm{HIV}$-positive donors have been detected during last 20 years, the incidence for HBV and HCV in blood donors is below 0.15 pro mille and $0.25 \%$, respectively. European standards have been

\begin{tabular}{ll}
\hline KARGER & $\odot$ 2006 S. Karger GmbH, Freiburg \\
Fax +497614520714 & Accessible online at: \\
$\begin{array}{l}\text { E-mail Information@Karger.de } \\
\text { www.karger.com }\end{array}$ & www.karger.com/tmh
\end{tabular}

E-mail turek.petr@centrum.cz 
accepted and implemented during the last 15 years, with safety (quality) and general availability being the priorities. Donor selection, blood collection, processing, and testing comply with EU directives. Manufacturers of blood components (blood establishments) are under the control of the state authority (State Institute for Drug Control). Recommendations based on expert opinion are available for clinical use of blood. Adverse effects of treatment are followed and investigated. Costs of blood components and plasma products are covered by the general health insurance $[1,2]$.

\section{Organization}

There are two types of organizations handling human blood in the Czech Republic, blood establishments and blood banks. Blood establishments collect blood and produce blood components and/or plasma for further processing. In March 2006, there has been 82 blood establishments. 55 of them cover donor recruitment, selection, blood collection, processing and testing ( 8 centers are licensed for mobile collections as well), 16 blood establishments are licensed only for blood collection (e.g. blood collection centers), and another 11 blood establishments collect and process only autologous blood. By size (number of collections processed) blood establishments vary between 3,000 and up to 40,000 whole blood units processed per year. All blood establishments, except for two, are an organizational part of a regional or university hospital. These facilities (hospitals) are usually owned by the state or regional authorities. There are no commercial plasmapheresis centers in the Czech Republic. Due to this structure, blood establishments work independently from each other, and cooperation is limited. Some centralization occurs slowly and spontaneously during the last 10 years. Twelve previously 'full-scope' blood establishments were transformed into blood collecting centers and/or became integral parts of a larger establishment.

A blood bank is an organizational unit of a health care facility which stores and provides blood components and carries out pre-transfusion testing for exclusive use within the health care facility. In hospitals where an blood establishment is located a blood bank is usually joined with it. In small hospitals in the countryside, the blood bank is joined with biochemistry, hematology, and transfusion medicine into one department.

There is no plasma-processing factory in the Czech Republic, and plasma for fractionation is sent for processing abroad. Stabile plasma products made from pooled plasma are re-imported according to real needs.

\section{Responsibilities}

The Ministry of Health bears the general responsibility for the health care, including blood transfusion services, In 1996 the Ministry of Health prepared a new conceptual document deal- ing with blood transfusion services. Safety (quality) and general availability had been set as the highest priorities. Self-sufficiency based on voluntary non-remunerated donations is a goal. Responsibility on quality control had been delegated to the State Institute for Drug Control. Since 1991 (with few interruptions), an advisory body, the National Blood Transfusion Committee, consisting of blood bankers, clinicians, epidemiologists and representatives of the state administration, control institutions (State Institute for Drug Control, Public Health Officer), health insurance companies and red cross organization is working in the Ministry of Health. A special Ministry of Health working group had prepared contingency plans to be followed in case of emergency (mass disaster, terrorist attack, etc.). Several major hospitals, most of them having also 'blood establishment' within their organization, are asked 'to be prepared' to supply basic health care, including blood transfusion service, in such a situation.

\section{Legislation}

Since early 1960s, blood transfusion service has been considered as a part of health care. The Law of the Health (20/1960 Coll.) set the obligation to prepare and use blood components 'lege artis'. Several non-binding recommendation on donor selection, blood collection, product preparation, storage, and use have then been prepared by expert groups under the auspices of the Ministry of Health during 1960s and 1970s.

The first legally binding document regulating good manufacturing practice (GMP) in the Czech Republic was the GMP Decree 284/1990 Coll. issued in 1990. This document was based on the GMP guide prepared by the PIC/S (Pharmaceutical Inspections Convention/Scheme) expert group in 1983 and covers all aspects of a production of blood components and plasma for fractionation, starting with selection of materials, over collection and processing to storage and distribution. This decree was binding for the manufacturers of medicinal products and pharmaceutical ingredients as well as for wholesalers of medicinal products. The system of licensing of manufacturers of medicinal products and pharmaceutically active ingredients and of wholesalers of medicinal products was established by the amendment of the Law of the Health in 1992. The Drug Act 79/1997 Coll. introduced licensing of blood establishments and amended compulsory GMP requirements for blood establishments. The update of the Drug Act 79/1997 Coll. from 2000 categorized the activity of blood establishments as a manufacture (it was considered to be a 'preparation' with a softer regulation earlier). Decree 298/2000 Coll. contains for the first time specific GMP requirements for blood establishments (premises, documentation, production, release of a blood component for therapeutic use and/or used as a starting material for further manufacture, receipt and supply of blood components and blood derivatives, etc.). The actual version of the GMP Decree (No 411/2004) added regula- 
tions for good distribution practice (GDP), detailed conditions for granting authorizations for the manufacture and distribution of as well as detailed conditions for the authorizations for control laboratories.

Several additional amendments of the Drug Act and GMP Decree have been adopted since then to harmonize Czech and EU legislation, but these changes were not principal ones as far as Czech legislation introduced the principles of EU legislation even before Blood Directive (98/2002/EC) has been adopted. Some small issues still have to be transposed according to technical directives to 'blood' directive (34/2004/EC; 61/2005/EC and 62/2005/EC), and the new versions of the Drug Act and GMP Decree for Blood Establishments and Blood Banks are now discussed in the Parliament and in the Ministry of Health. Adoption of these regulations is expected in this year.

\section{Standards and Recommendations}

Blood establishments, blood banks and clinicians are required to take into account recommendations of the Council of Europe, European Commission, WHO, the measures of the Ministry of Health and the State Institute for Drug Control, and recommendations/standards prepared by expert groups of the Czech Medical Association (one of its branches is the Society for Transfusion Medicine) [3-9]. An indirect but very important regulatory role play standards for payment of different blood components agreed by Ministry of Health, health insurance companies and medical society (including the Czech Society for Transfusion Medicine).

\section{Accreditations and/or Certifications (Licensing) of Blood Establishments}

The State Institute for Drug Control is set to be a competent authority for issuing licenses and manufacturing authorizations, changes and cancellation for blood establishments and to perform for GMP inspections. Since 1997, all blood establishments are required to be licensed, and since August 2002 they must have a manufacturing authorization. The scope of activities of an individual blood establishment is specified in the manufacturing authorization, and the change of activities (for example from blood donations to processing of the whole blood or introducing apheresis) calls for re-edition of the license. Such a change usually calls for GMP inspection. Manufacturing authorization includes name and address of the license holder, its identification code, the scope of activities performed, the names of qualified persons, and a list of subcontractors. According to the law, any blood establishment should pass GMP inspection performed by the State Institute for Drug Control every other year. Besides regular ones, inspections on request are performed (due to changes in activities, request from the state authority, etc).
A blood bank is not obliged to have any license or authorization but it should be registered. Blood banks should, within the scope of its activities, ensure compliance with GMP, and they are monitored (and inspected) by the State Institute for Drug Control as well (but not at regular, bi-annual basis).

\section{Quality Systems and Policies}

Quality is in the responsibility of all persons involved in collecting blood and preparing blood components. Blood establishments must adopt all necessary measures to ensure that a quality system is implemented and maintained. The quality system involves all activities that determine the quality policy, objectives, and responsibilities and implement them by such measures as quality planning, quality control, quality assurance and quality improvement within the quality system. There are units within the blood establishment structure which are independent of preparation and fulfil quality assurance and quality control responsibilities. The quality assurance unit is involved in all quality-related matters. This unit reviews and approves all appropriate quality-related documents.

A formal change control system has to be in place to evaluate and document all changes that may affect the collection, preparation, storage, dispatch, quality control and quality assurance of blood and blood components. The potential impact of a proposed change has to be evaluated. Scientific judgment should determine what additional testing and validation studies are needed to justify a change in a validated process. Before the commencement of supply of a new product, the blood establishment shall validate the compliance of the product with all quality requirements.

A system for self-inspection has to be implemented. Self-inspections are performed under the responsibility of the quality assurance unit by qualified persons to verify compliance with the principles of GMP and regulatory requirements. Self-inspection comprises all parts of the operations. They have to be performed regularly, and results have to be documented.

A system for prevention of quality failures and implementation of corrective measures must be implemented. The system should ensure that existing product nonconformity or quality problems are corrected and that re-occurrence of the problem is prevented. Quality data are routinely analyzed to identify problems and/or unfavorable trends. Corrective actions should be documented and completed in a timely and effective manner.

\section{Quality Assurance}

The quality assurance system must ensure that all critical procedures are specified in appropriate instructions, are performed in accordance with the principles of GMP, and comply with competent health authority regulations. The system should be reviewed by the blood establishment management at regular intervals to verify the effectiveness of the system and introduce corrective measures if deemed necessary. 


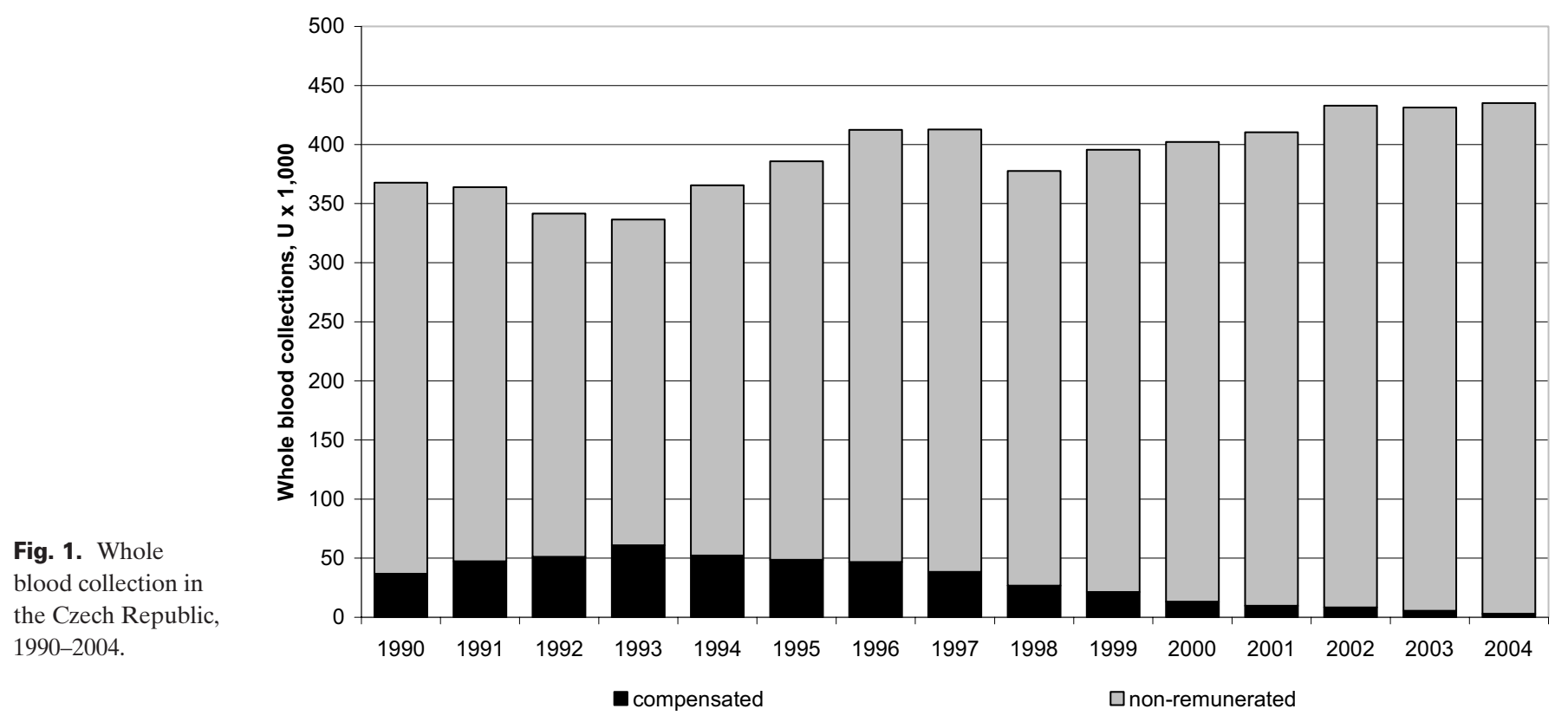

\section{GMP Inspections}

The first inspection groups were established in former Czechoslovakia in the State Institute for Drug Control. The milestones of GMP inspection system are:

- in 1988 Czechoslovakia took part in WHO certification scheme,

- in 1996 Czech State Institute for Drug Control took part in $\mathrm{PIC} / \mathrm{S}$,

- in 2002 PECA (Protocol to the European Conformity Assessment) agreement between the Czech Republic and the European Commission was approved. This agreement confirmed equivalence of state GMP inspection system with systems operated within the community.

The first state GMP inspection in pharmaceutical industry started in 1985, and in 1994 first GMP inspections started in blood establishments. One year later, the inspections in blood establishments started to be compulsory.

Inspection activities of the State Institute for Drug Control related to the manufacture of pharmaceuticals are performed in accordance with the provisions of Czech legislation, with the Institute's guidelines, with the guidelines issued by the European Commission and with recommended PIC/S procedures. Basic requirements for the procedure applicable to the conduct of inspections as well as measures available for the case of a serious breach of the Act on Pharmaceuticals and related regulations are stipulated by Act No 552/1991 Coll. and by Drug Act No 79/1997 Coll. In the conduct of inspections, inspectors also follow the procedures and requirements stipulated by Compilation of Community Procedures on Inspections and Exchange of Information. The types of inspections, preparation and conduct thereof, the evaluation of the degree of GMP and GDP compliance, where applicable, preparation and presentation of the Inspection Report, handling of corrective action by the manufacturer, instigation for further State Institute for Drug Control action against the manufacturer, and the quality control procedure governing the entire process are described in standard operating procedures (SOPs) to guarantee a standard conduct of an inspection, including accurate, factually correct and impartial protocols. Criteria have been defined for the development of the inspection plan. In all inspection-related activities, conformity with the principles of the quality management system stipulated by EN ISO 9001:2001, EU recommendations and PIC/S recommendations is being ensured.

Czech GMP inspectors take part regularly in all activities of $\mathrm{PIC} / \mathrm{S}$, including special sections devoted to the area of blood centers. Several joint inspections with foreign inspectors in the Czech Republic and training of Czech inspectors abroad (Austria, UK) have been organized in the past. Representatives of State Institute for Drug Control take part on EMEA/CPMP blood and plasma working party and on 'ad hoc' meetings of GMP inspectors.

Blood establishments which send their plasma for processing to a commercial plasma-processing company are inspected on a regular basis by these companies. Major blood establishments are on a voluntary basis inspected by ISO-certifying agencies and several of them are already certified to the EN ISO 9001:2001.

\section{Donor Epidemiology and Infection Marker Testing}

The pool of voluntary non-remunerated donors in the Czech Republic is currently large enough to ensure self-sufficiency in blood components and plasma for fractionation. Blood dona- 
Fig. 2. Proportion of different types of red cell concentrates produced in 1995-2004.

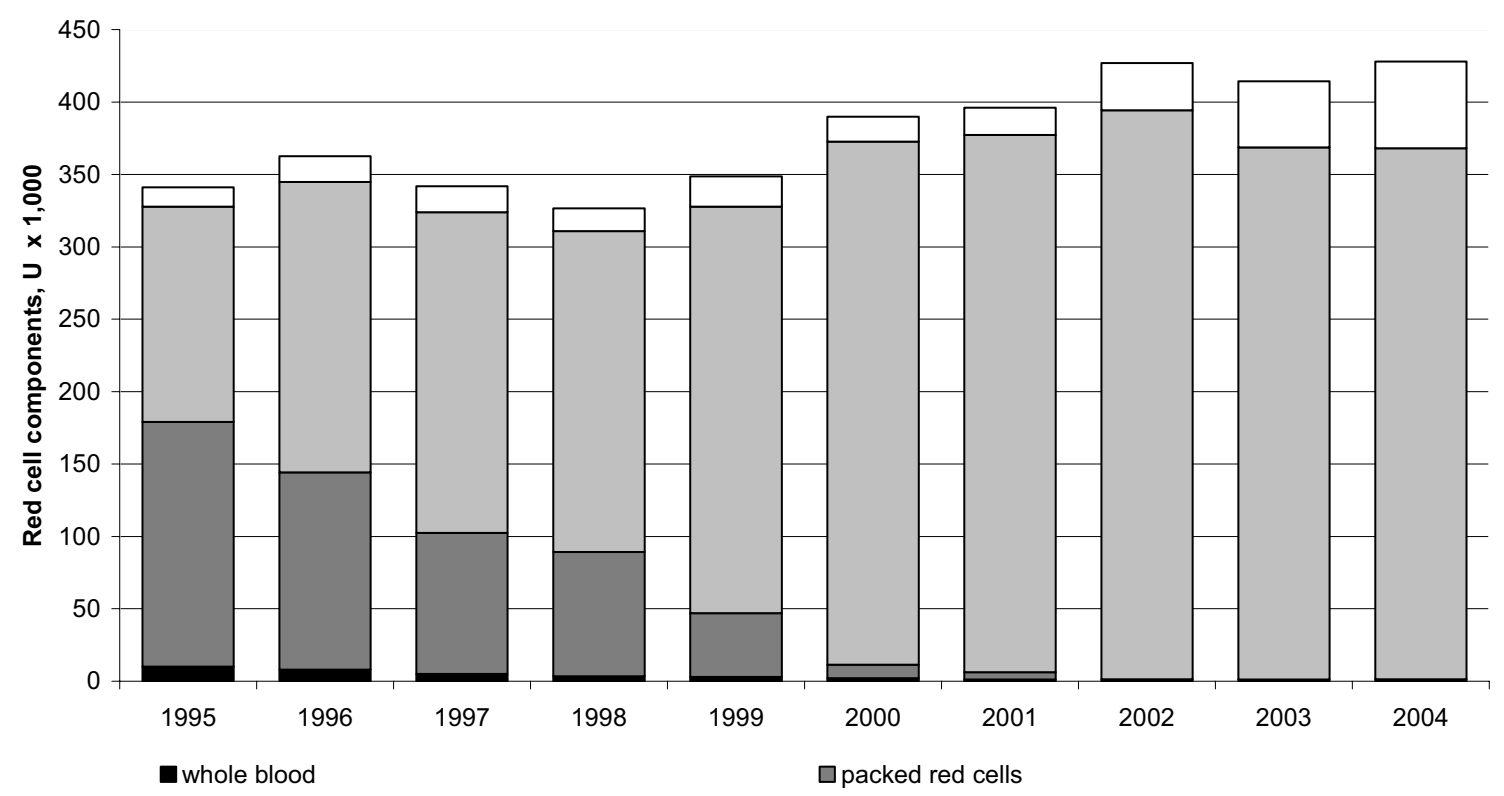

$\square$ packed red cells in additive solution, buffy-coat removed $\square$ packed red cells in additive solution, leukocyte-depleted
Fig. 3. Production of platelet concentrates 1995-2004 (therapeutic doses $=200-300 \times 10^{9}$ )

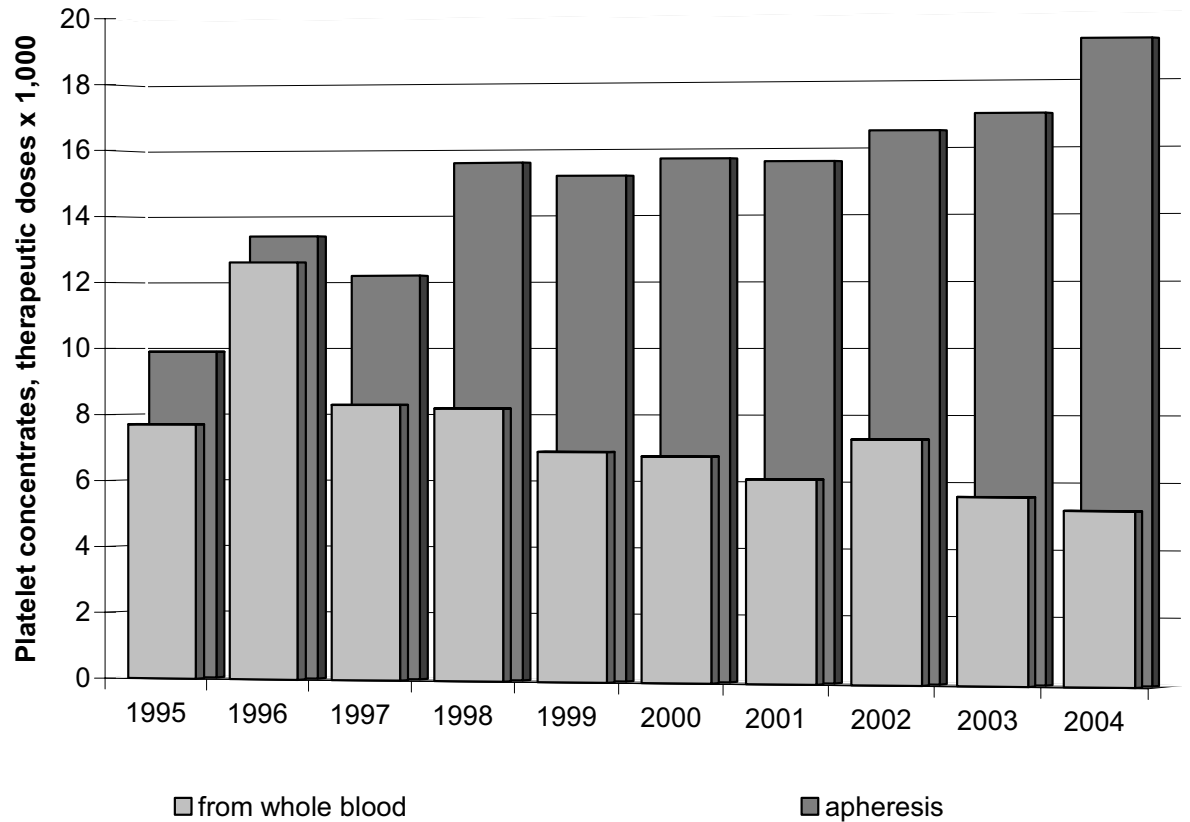

$\square$ from whole blood $\square$ apheresis tion has a relatively high public prestige. The donor pool is stable; the turnover is less then $10 \%$ per year. The vast majority of whole blood collections (over $99.5 \%$ ) is performed without any direct payment to donors, about two thirds of apheresis donors are compensated for travel expenses and time lost (EUR 10.- to 30.- per donation). Donors are registered locally in the individual blood establishment but information on rare blood groups donors and donors excluded from donation due to carriership of infection is shared. Eligibility of a blood donor is investigated in accordance with EU legislation; donors are interviewed by a qualified physician in the majority of settings before donation. Blood donor questionnaires and information leaflets on risk of infection for blood recipients and risk activities are available.

Collected blood is tested for markers of HIV (antibodies and p24 antigen combined test), HBV (surface antigen), HCV (antibodies or antigen + antibodies) and syphilis (antibodies) in accordance with the EU directive. NAT testing as a screening test is currently not performed. All repeatedly reactive samples are sent for confirmatory testing into the National Reference Laboratory. All laboratories testing infectious markers in blood transfusion services should be licensed by the State 
Fig. 4. Production of plasma in 1995-2004.

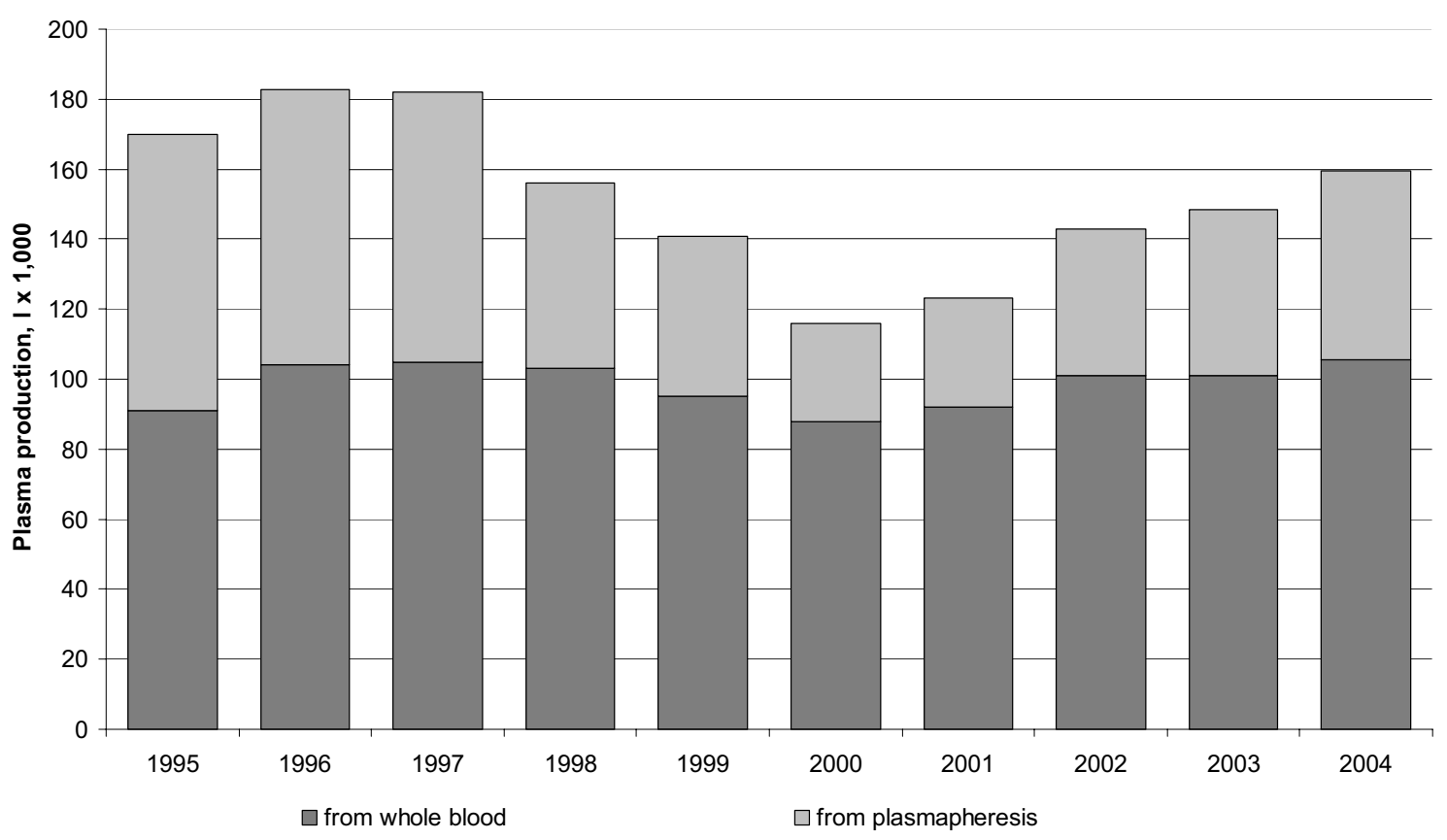

Institute for Drug Control. They have to take part in a proficiency testing schema. The epidemiological situation in the Czech Republic is relatively good and stable: a total of 19 HIV-positive donors have been detected since HIV testing was implemented in 1986 (circa 1 per year); a few dozens of HBV- and/or HCV-positive donors are picked up per year (cumulative incidence of confirmed positive and indeterminate results was $0.14 \%$, i.e. 75 cases for $\mathrm{HVB}$, and $0.25 \%$, i.e. 134 cases for $\mathrm{HCV}$, in 2004).

\section{Production}

Over 400,000 whole blood units are collected per year giving circa 40 units per 1,000 of inhabitants. This number is stable over the last years (fig. 1). Approximately $4.5 \%$ of red cell consumption is covered by autologous pre-deposit donations. Practically all whole blood collected is processed into components. Buffy-coat depleted, packed red cells cover ca. $85 \%$ of red cell consumption. The proportion of leukocyte-depleted red cell concentrates is increasing being $12-15 \%$ in last years (fig. 2). The production of platelets is slowly increasing being now 25,000 of therapeutic doses $\left(200-300 \times 10^{9}\right)$; three fourths of platelets come from single donor apheresis, and one fourth is derived from whole blood using the buffy-coat technique (fig. 3). Human leukocyte antigen(HLA)- and/or human platelet antigen(HPA)-matched platelets are available if necessary. Plasma donation by means of instrumental plasmapheresis was very popular in mid-1990s, then plasma collection dropped down due to the surplus of plasma and now is recovering again. Over 100,000 1 of plasma from whole blood collections and over 50,000 1 of plasma from apheresis are produced per year (fig. 4). Plasma for clinical purposes is kept in quarantine for 6 month. Approximately 80,000-90,000 1 of fresh frozen plasma (both from whole blood collection and apheresis) is sent for fractionation abroad annually. Consumption of albumin dropped in mid-1990s to $90 \mathrm{~g} / 1,000$ inhabitants. Consumption of intravenous immunoglobulins is ca. $19 \mathrm{~g} / 1,000$ inhabitants. Consumption of coagulation factors is increasing being nowadays over $2.8 \mathrm{IU} /$ capita for factor VIII.

\section{Hemotherapy}

Transfusion therapy has a long tradition in the Czech Republic. Strict rules for transfusion have been developed. Only an experienced clinician is allowed to indicate transfusion and only nurses with special training are allowed to apply transfusion. Any transfusion has to be performed under the responsibility of a physician. Any transfusion should be documented in the patient's record together with evaluation of clinical outcome and, if detected, post-transfusion adverse reaction. Within a hospital, a 'transfusion committee' has to be established, reviewing transfusion policy. Unfortunately, these committees are working properly in only a part of the hospitals. Indication criteria of blood components are agreed between clinicians and health insurance companies (under the auspices of the Ministry of Health and the National Blood Transfusion Committee). Only products applied within agreed indications should be reimbursed. (In case when a medical consultant of a health insurance company does not approve the indication for transfusion, the product is not reimbursed to the hospital, but this happens rarely. The patient is not charged in any case). 
In general, blood products are considered to be safer then ever, but inherited risks connected with their use are understood even by a public (the Czech population has no experience with 'blood-related AIDS' in the 1980s). Blood-sparing techniques and alternative treatment modalities are available and widely used (from volume expanders to erythropoietin, hemodilution and autologous transfusion) but many experts argue that the use of blood (and especially of plasma) in real practice should be much lower.

\section{Immunohematology and Pre-Transfusion Testing}

Immunohematological and pre-transfusion testing is widely available and not centralized; special immunohematology (rare blood group typing, HLA, platelet and granulocyte immunohematology, etc.) is available only in regional and/or university hospitals. Unexpected findings could be sent to the National Reference Laboratory for Immunohematology located in the Institute of Hematology and Blood Transfusion in Prague. Blood banks are usually located within a hospital, only hospitals with very limited needs of blood components are supported by a blood bank from outside. If a patient has a set of irregular antibodies, a National Rare Blood Group Donor Registry is available, and access to international blood banks is guaranteed. Although blood grouping supplemented with antibody screening is performed in a prospective transfusion recipient as a standard procedure, full-range cross-match analysis is usually applied before red cell transfusion. Computer cross-matching is performed only in a small number of hospitals. To minimize the risk of mis-transfusion, bedside blood grouping is performed before red cell transfusion. Pretransfusion samples and residuum of the product is kept for reconstruction of product selection in case of doubts.

\section{Hemovigilance}

Adverse reactions to blood transfusion and epidemiological data of blood donors have been collected for several decades (since the 1970s) in the Czech Republic. All types of adverse effects and reactions have been reported to local and/or central authorities (serious ones) regardless of the cause (both patient- and product-related and also personnel mistakes). The grading for transfusion imputability has not been involved in those times. Severe reactions were reported to the Ministry of Health and reviewed by an expert committee. Corrective actions were then recommended and applied.

Nowadays (since 1997) blood components and plasma products are classified as medicinal products (drugs), and serious side effects have to be reported according to the rules of pharmacovigilance. This means that obligatory reporting is limited to blood product quality defects only (including infection transmission). Actual legislation delegates the responsibility for data collection to the State Institute for Drug Control. There is no legal obligation to report other than 'product-related' reactions and adverse events (patient-related reactions, bad clinical practice, hospital staff mistakes and near-misses) as the former system is no more effective. Some data are collected by the Czech Society for Transfusion Medicine on a voluntary basis, but there is a general feeling of under-reporting as far as clinicians probably do not report all reactions and adverse events to the blood bank. Investigation of suspected viral transmissions is provided by the National Public Health Service. Any infection with blood-borne pathogens diagnosed in a patient should be carefully investigated for possible exposition to blood components or plasma products in the past. Any carriership of HIV, HBV or HCV infection in a donor is reported to the blood transfusion service. A complex system of look-back within the blood transfusion service is implemented too.

Since 2005, the collection of data about serious adverse or unexpected reactions in donors or recipients and serious adverse events associated with the collection, testing, processing, storage and distribution of blood and blood components has started. But this reporting is not supported by legislation yet. The New Drug Act which is now discussed in the Parliament should design reporting of adverse events and reactions in accordance with the European legislation.

\section{Financing}

Costs of blood components and stable plasma derivatives used for treatment are covered by the general health insurance. Prices of blood components and stable plasma derivatives are submitted to regulation through the Ministry of Finance and the Ministry of Health. The blood establishment sells its product to the hospital, and the hospital asks the health insurance company of a given patient for reimbursement. Prices of individual products to be reimbursed by health insurance companies to hospitals are set by a committee of experts and representatives of state and health insurance companies and are published as Ministry of Health decree.

Other services supplied by blood establishments and/or blood bank (laboratory testing of a patient, cross-matching, etc.) are also covered from health insurance. Laboratories/hospitals charge the health insurance company of a given patient, and services are reimbursed according to the pricelist published as Ministry of Health decree.

\section{Perspectives and Challenges}

There are organizational and scientific tasks and challenges for the Czech blood transfusion service in the near future. The organizational structure of institutions collecting and processing blood should be discussed to support coordinated and cost-ef- 
fective production of safe products. The adoption of an amended Drug Act completely transposing EU directives into Czech legislation in the field is expected. A lot of effort should be paid to donor recruitment and education to ensure a sufficient pool of safe donors (building up a national system for donor recruitment). Methods of infectious marker testing should be re-evaluated, and the implementation of tests with shorter window periods should be re-considered, especially for HCV. Quality and safety of the product are under permanent control, and modern, advanced products should be introduced immediately when their efficacy and safety is proven (for example leukocyte-depleted products should be used in all patients where the evidence is showing benefit). Laboratories of special immunohematology should be re-designed to guarantee availability of services also in non-working hours. Indications for transfusion should be regularly updated and alternatives to transfusion should be sought for. More attention should be paid to adverse effects of blood transfusion, and a hemovigilance system should be strengthened (nowadays the follow-up of product-related adverse effects is under the responsibility of the State Institute for Drug Control, but there is not a system for follow-up of patient-related reactions).

\section{References}

1 Rouger P (ed): Blood Transfusion in Europe. The White Book 2005, Paris, Elsevier, 2006.

2 Rokosova M, Hava P, Schreyogg J, Busse R: Health Care Systems in Transition: Czech Republic, Copenhagen,WHO, 2005.

3 Council of Europe R (95) 15: Preparation, Use and Quality assurance of Blood Components, 12th ed. Strasbourg, Council of Europe Publishing, 2006.
4 EU Council Recommendation 98/463/EC on the Suitability of Blood and Plasma Donors and the Screening of Donated Blood in the European Community.

5 Blood Donor Suitability: Bulletin Ministry of Health of the Czech Republic, No.1/1998.

6 Manufacture of Medicinal Products from Human Blood Or Plasma: Bulletin State Institute for Drug Control, VYR:32 Annex 14.
7 GMP Guide for Blood Establishments: Bulletin State Institute for Drug Control, VYR:25, (translation of GMP PIC/S Guide)

8 Standard for Labelling of Transfusion Products: Bulletin Ministry of Health of the Czech Republic, No. 9/2003.

9 Licensing System for Blood Establishments: Bulletin State Institute for Drug Control, VYR:29, (translation of EU GMP Annex). 